\title{
CRÓNICAS DEL DESPENADOR
}

\author{
Carlos Arrizabalaga \\ carrizabalaga@csumb.edu
}

\begin{abstract}
RESUMEN: En algunas zonas rurales de Sudamérica se ha señalado la presencia de un personaje oscuro y temible conocido como "el despenador", que acorta la vida de los agonizantes a petición de los familiares. Esta forma de eutanasia campesina o indígena, pese a tener una presencia casi insignificante, ha dado lugar a un motivo literario en seis relatos escritos por igual número de narradores peruanos a partir de un breve pasaje de las Tradiciones peruanas de Ricardo Palma y un cuento ya clásico de Ventura García Calderón. También aparece con alusiones fugaces en dos novelas de Mario Vargas Llosa y en una de la argentina Cristina Bajo. La figura del despenador se presenta bajo formas muy variadas aunque en todos los casos se caracteriza por su desintegración social y su descomposición moral.
\end{abstract}

PALABRAS CLAVE: cuento literario, eutanasia, folclore, Perú, Ricardo Palma, Ventura García Calderón

ABSTRACT: In some rural areas of South America the presence of a dark and fearsome character has been known as "el despenador" (a kind of killer-shaman) who shortens the life of those in agony at the request of relatives. This form of indigenous or peasant euthanasia, although practically non-existent, has given rise to a literary motif in six stories written by six Peruvian authors, based on a short passage in "Tradiciones peruanas" by Ricardo Palma and on a now classic tale by Ventura Garcia Calderón. Passing allusions also appear in two novels by Mario Vargas Llosa and in a novel by the Argentinian writer Cristina Bajo. The figure of the "despenador" is presented in the most varied ways but he/she is always characterized by social disintegration and moral degeneration.

KEYWORDS: short stories, euthanasia, folklore, Peru, Ricardo Palma, Ventura Garcia Calderón

Las tradiciones populares siempre han ofrecido a los escritores multitud de temas y personajes. En el Perú, por ejemplo, la leyenda en torno al pishtaco, el degollador que mata a los viajeros para robarles su grasa, dio un motivo a Mario Vargas Llosa para escribir Lituma en los Andes (1993). Nuevos escritores siguen encontrando motivos interesantes para sus relatos, como Jorge Nájar, quien hace aparecer en una reciente novela las sombras de muquis, tunchis, chullachaquis y pishtacos (2014: 68).

En algunas zonas rurales como el desierto costero norperuano, el altiplano de Perú y Bolivia y todavía más allá, en el noroeste argentino, se ha señalado la presencia de un personaje oscuro y temible que por lo general se conoce como "el despenador". El término está recogido por el padre Esteban Puig en su Diccionario folclórico piurano, con un significado algo esquivo: "Persona que con sus perjurios y ritos ayuda a morir a los enfermos desahuciados" (1995: 94). Arámbulo Palacios lo describe como una realidad del pasado: 
"Hombre con aspecto de ave agorera. Persona malvada que solía eliminar a los enfermos." (1995: 89). ${ }^{1}$

El doctor José Manuel Marroquín señalaba que en Puno, en los años cuarenta del siglo XX, estaba aún muy generalizada la creencia de que el agónico exhala el "apostema" o aliento contagioso que enferma a quienes cuidan al paciente. Es por eso que le echaban un lazo al cuello y lo estrangulaban "para que no salga el apostema". La explicación que daban en Piura a esta solución dramática, tal como lo señala Moscol Urbina (2008: 134) es que de esa manera evitaban que el difunto tuviera que regresar a la tierra a "recoger sus pasos". De hecho los norteños acostumbran a no barrer las casas de los difuntos con la presunción de que el alma de los difuntos suele regresar siempre a su casa para recoger sus huellas, y no pueden hacerlo si con la escoba se borran los últimos pasos que dio en el piso o suelo del domicilio.

Mucho más al sur, el arqueólogo, lingüista y etnólogo uruguayo Samuel Lafone Quevedo describía por su parte la "vieja costumbre" de despenar agonizantes en lugares remotos de Argentina o Bolivia (Vivante, 1953: 10). En Catamarca, Salta y Tucumán, en el norte de Argentina, ciertas mujeres eran llamadas para ultimar a aquellos enfermos que prolongaban demasiado la agonía de la muerte. Aunque tales prácticas fueron insistentemente perseguidas por las autoridades civiles y religiosas, estaban tan profundamente arraigadas en el pueblo, especialmente rural, que no creían que fuese ni pecado venial el anticipar a aquellos infelices dolientes el tránsito "con un movimiento artístico que les quebraba el espinazo", pero claro que tales mujeres eran luego mencionadas para asustar a los niños (Vivante, 1956).

La muerte se disfraza siempre y la propia palabra "despenador", hoy en desuso, era un eufemismo por verdugo igual que "deshecho", "desperdicio" o "deposición" esconden la fealdad de palabras como "basura", "suciedad" o "excremento". El reconocido médico forense español José Manuel Reverte Coma, relataba otros ejemplos de despenadores entre los esquimales o los indios cuna de Panamá, país que fue su residencia durante 17 años y donde desarrolló una enorme labor también en el ámbito de la cultura, lo que le valió además fondos del Instituto Smithsoniano y numerosos premios. Con una obra científica más que notable, destacó que todas las culturas, en general, muestran enorme respeto por los ancianos, a los que protegen y cuidan incluso más que en los países civilizados justo porque valoran especialmente su experiencia. El fenómeno de la eutanasia es en las culturas antiguas algo marginal y está restringido a condiciones en que el agonizante pone en riesgo a la comunidad tribal, sea por el peligro de contagio o por la necesidad vital de desplazarse a otros espacios.

En realidad se trata de un motivo literario más que una realidad pues no se comprueba vigente en ningún espacio en que se haya reportado en la historia cultural latinoamericana. Y como vamos a poner de relieve en este trabajo, se convirtió en un tópico con cierta recurrencia en la tradición peruana, apareciendo como protagonista o como personajes

\footnotetext{
${ }^{1}$ El verbo despenar fue usual en el Siglo de Oro con el sentido de quitar los pesares y así lo define Covarrubias (2006: 693) y así lo usa Cervantes en El juez de los divorcios: "Si fuese possible recebiría gran merced que vm me la hiciesse de despenarme alçándome desta carcelería". El significado de 'matar enfermos desahuciados' lo trae María Moliner para Sudamérica y Alcalá Venceslada para Andalucía: “ayudar a morir a quien se encuentra en ese trance" (1998: 224), aunque se aplica principalmente a animales. Morínigo (1998: 248) define despenar como "rematar a un animal que está moribundo", restringiendo su uso al Río de la Plata. Neves daba esta acepción también a Guatemala. Sin embargo, Abad de Santillán lo aplica claramente a personas en primer lugar, y da una pista del posible origen de despenar, vinculándolo con las guerras de Independencia (trae una cita de L. Mansilla) y las luchas civiles que le siguieron: "Matar al moribundo o al que está herido de muerte, para que deje de penar o padecer. Se usa también refiriéndose a animales. En el pasado fue una práctica militar impuesta por la circunstancia de carecer los ejércitos de cuerpos de sanidad."(1976: 171).
} 
secundario de seis relatos de otros tantos escritores, además de dos menciones pasajeras en sendas novelas de Mario Vargas Llosa. La mayoría se sitúan en la región norperuana, que es muy rica en curanderismo, creencias populares y supersticiones religiosas. Un análisis de los documentos de persecución de idolatrías realizado por Laura Larco en la zona de Trujillo descubre acusaciones de hechicería, brujería, engaño con supersticiones, maleficio y calumnia de brujería, en algunos casos asociados con crímenes; sin embargo, ninguno en torno a casos de despenadores (2008: 39).

Cabe pensar que el despenador apareció en realidad en las turbulentas décadas de mediados del siglo XIX y que pervivió hasta inicios del siglo XX. Como figura literaria, el origen del despenador se sitúa en una escena cómica de la quinta serie de las Tradiciones peruanas de Ricardo Palma, aunque como tal, valgan verdades, el primero que desarrolló todo un relato alusivo a esta figura tenebrosa fue el escritor también peruano Ventura García Calderón. En ambos aparece asociado a un tratamiento humorístico del terror y la muerte por medio del malentendido y la sorpresa.

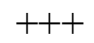

En la Tradición "Juan Sin Miedo" de Ricardo Palma, como dije, asoma brevemente el término. "Fray Juan sin miedo" está fechado, según Díaz Falconí (2005: 93), en el año 1878, pero se publica por primera vez en La Prensa el 29 de julio de 1883, incluyéndose en la quinta serie de las Tradiciones en las ediciones de Prince (1883) y Montaner y Simón (1994), que es la que citamos. ${ }^{2}$

El joven fraile no tiene miedo a nada ni siquiera cuando que el difunto que está velando se incorpora en plena noche. Y en lugar de salir corriendo le emplaza: “¿Estaba vuesa merced dormido o viene del otro mundo a algún negocio que se le había olvidado? Acuéstese como pueda y durmamos en paz, si no quiere que le sirva de despenador?" (1894: 36). Pero el agonizante responde con un candelabro la amenaza del fraile lego y lo deja desmayado antes de caer muerto definitivamente. $\mathrm{Y}$ el otro desde entonces se vuelve manso como un cordero. Palma hace entonces una de sus acostumbradas digresiones para señalar al despenador como "un oficio como otro cualquiera", que recibía buenos emolumentos y era desempeñado habitualmente por gente solitaria: "era un indio de feo y siniestro aspecto que habitaba siempre en el monte o en alguna cueva de los cerros" (1994:36).

Según Ricardo Palma existieron en muchos pueblos del Perú, aunque seguramente exageraba un poco. Lo justifica por el deseo de los parientes de no prolongar más de lo necesario la agonía. El último que actuó en Huacho -bromea Palma- había desaparecido hacía cincuenta años y desde entonces tal oficio había desaparecido. Recibía con antelación dos o cuatro pesos como pago por el servicio, que consistía en un estrangulamiento realizado con una uña "descomunalmente crecida" (1994: 36). Comprobamos ya unos elementos que se van a repetir en muchas versiones de este motivo: el talante indígena del despenador, su carácter solitario y tenebroso y su fealdad, asociada aquí a esa uña descomunal.

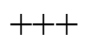

\footnotetext{
${ }^{2}$ Finalmente el título definitivo será Fray Juan Sinmiedo, a partir de la edición de Calpe (1924). Ver Díaz Falconí (2005: 93).
} 
Ventura García Calderón (1886-1959) publicó los cuentos de La venganza del cóndor en Madrid (1924) y de él se hicieron luego traducciones al francés, italiano y alemán, además de numerosas ediciones. Sus relatos figuran en la mayoría de las antologías y libros de texto nacionales, con lo que es uno de los escritores más conocidos para el público peruano. García Calderón mostraba un inusitado interés por las aldeas de la serranía peruana, una sociedad andina que solo conoció lejanamente y que le sirvió como marco extraño y alucinado para historias truculentas llenas de personajes desquiciados, situaciones difíciles, sorpresas y granes pasiones. De todos sus escritos destaca el inolvidable relato "El alfiler". Este ensayista, narrador y poeta peruano puede considerarse una de las figuras más relevantes de las letras peruanas modernas.

Hijo del presidente exiliado Francisco García Calderón (1834-1905) nació en París al igual que su hermano Francisco, también escritor y diplomático. Ventura estudió en Lima, la Universidad de San Marcos, pero regresó pronto a Francia y pasó finalmente buena parte de su vida en París; representó a su país primero en la Sociedad de las Naciones (1932), y luego en Bélgica (1935) y en Suiza (1940). Finalmente fue representante del Perú en la UNESCO, con sede en París. Fue uno de los pocos extranjeros incorporado a la Academia Francesa.

Suele considerarse un escritor modernista, junto con Clemente Palma y Abraham Valdelomar (Escobar, 1960: XX) especialmente por su poesía y su espíritu refinado, enamorado de lo francés. Sus cuentos también participan del movimiento modernista pero tienen un carácter más tenebroso, acercándose a la literatura gótica y a influencias de Poe o Maupassant, más vinculado al decadentismo europeo de fines del siglo XIX. Fue el escritor peruano más internacional hasta la llegada de Cesar Vallejo y Ciro Alegría. Luego de haber sido postergado en las décadas del indigenismo y opacado por el famoso boom, ha sido últimamente reinstalado dentro del canon literario nacional, y empieza a conocerse más su obra que es realmente diversa y abundante, gracias también a la selección de su narrativa que publicó Luis Alberto Sánchez (1989) y ahora por la edición de su narrativa completa a cargo de Ricardo Silva Santisteban (2011).

La venganza del cóndor es sin duda su mejor colección de cuentos, pero cabe destacar también los relatos del libro Color de sangre (1931), con prólogo de Blasco Ibáñez; algunos otros están agrupados con los títulos Dolorosa y desnuda realidad (1914) y Peligro de muerte. Además cabe mencionar los poemas de Cantilenas y Semblanzas de América (1920), ni las crónicas de Frívolamente (1909), y otras; pero sí que tienen interés singular ensayos como Del romanticismo al modernismo (1910) y sus estudios además de sus importantes ediciones en la Biblioteca de Cultura Peruana, realizadas bajo la presidencia de Oscar Benavides. García Calderón representa el americano refinado y culto que se instala en Europa pero mira hacia Hispanoamérica, difundiendo la imagen de un continente fascinante a la vez que trasmite a sus connacionales las novedades culturales del viejo mundo.

En lugar de juzgar sus dotes literarias (elogiadas entre otros por Gabriela Mistral, en 1927) la crítica se ha centrado más en criticar la falta de realismo de sus relatos fantásticos, su pobre conocimiento del mundo del indio y después su posicionamiento ante la problemática social, pero son "razones que escapan a lo propiamente artístico" (Escobar, 1960: XIX). Para José Miguel Oviedo, García Calderón observa al indígena como un turista en su tierra, lo ve desde lejos como un objeto curioso, buscando en él lo exótico lo extraño, lo misterioso, lo fascinante" (1969: 232). En efecto, el mundo andino representado en sus relatos resulta artificioso y caricaturesco, pero responde al propósito estético de inventar un ambiente cegado por el resentimiento y la violencia. Para Cornejo Polar, esta ensoñación responde a "una ideología oligárquica" que trata de legitimar la violencia e injusticia a través 
de un marco de irrealidad que encubre "su adhesión a un estado social y la defensa de los intereses de los grandes señores andinos" (1989: 46-48).

Efraín Kristal señala también en García Calderón la defensa del inmovilismo social de la oligarquía frente al indio, con la idea de "no despertar el atavismo de su raza" (1988: 66). El que lleva este argumento a un reduccionismo extremo es el profesor Escajadillo (1986: 51). El sufrimiento del indio sería "algo inherente al propio paisaje andino" (Veres, 2003: 69). Pero como afirmara Alberto Escobar, su narrativa muestra "la cosecha más espléndida en los predios modernistas" y reconoce "su interés por crear un estilo" (1960: XIX), así como el extraordinario valor de "su expresión sencilla y elegante" (Escobar, 1960: XIX). Asimismo cabe relievar su habilidad para crear en muchos de sus relatos una sensación fascinante y producir en el lector un efecto estético logrado, señalada ya, entre otro, por Ángel Flores (362).

Sin duda la generación modernista supuso una renovación cultural en Hispanoamérica. En este sentido cabría añadir la capacidad demostrada por García Calderón para crear en el personaje del despenador una figura literaria atrayente y persuasiva, que se manifestará en algo más de media docena de relatos de otros tantos escritores peruanos, algunos muy poco relevantes y sin duda de menor calidad, pero otros para qué rescatables y en algunos casos claramente apreciables tanto por su calidad literaria como por la fuerza de su imaginación.

Uno de los relatos de La venganza del cóndor (1924) ofrece una espantosa versión del asesino de enfermos con la sorpresa final de que la víctima se convierte en verdugo y el despenador en despenado. La acción se sitúa en algún poblado de la sierra del Perú, por la región de Huamachuco, en los Andes liberteños:

Lo habían ensayado todo sin éxito: el sebo de jaguar; la lana de llama blanca que alivia el dolor si se ha friccionado con ella el pecho enfermo; las hierbas serranas que el brujo del pueblo vecino propinaba en un mate de chicha después de haber escupido, como las llamas, hacia los malos poderes del aire. (191)

Se burla Ventura García Calderón de las viejas creencias y de que la Serafina pudiera volar hasta Huamachuco gracias a unos polvos amarillos a besar tres veces el trasero de un cabrito macho. El narrador muestra un descarado desprecio por la vida en los Andes. Los niños juegan con una rata monstruosa y los demás toman chicha y aguardiente. Y el que agonizaba era "un viejo cacique de indios" (191). Tomaba aguardiente pero se retorcía de dolor. Era necesario llamar al despenador, que era "un verdugo de buena voluntad, respetado y pagado" y se describe como "un indio hercúleo, de barbas ralas y solapado mirar estrábico", llevaba un poncho y pantalón de paño militar y "los pies roídos por la nigua mal curada" (192).

Colgaban de su cuello esas piedras - señala el narrador - que las gentes del país aseguran ser «ojos de gentiles», es decir, disecados ojos de muerto." Durante un rato tomó su chicha y chaccha la coca en la puerta para darse bríos. Avanzó hacia el agonizante, sujetó sus brazos y "le apoyó en el cuello el peso de su flaca rodilla". Esa era "la manera habitual de despenar". Pero siente "la mirada fría del cacique" y se sorprende de ver que el cacique se deshace de los nudos y se para ante la mirada aterrorizada del oficiante: “¡El cacique había recobrado aquella fuerza famosa que le permitía matar indios de un solo abrazo! (192). 
La familia aguardaba sin entender por qué tardaba tanto y al derribar la puerta vieron con espanto que el cacique había llevado al despenador hasta el fogón y agonizaba allí, carbonizado ya "con el rostro adolorido y anguloso de las momias" (192). El cacique no les reprochó nada:

Matar a los moribundos era la costumbre inmemorial, y él la acataba como todos. Pero él estaba vivo, fuerte, lozano. Para probarlo levantó a un cerdo en brazos y salió entonces al aire libre, masticando la coca amarga, a beber y bailar con toda la parentela serrana que preparaba el funeral. (192)

La sorpresa del final, la eficacia expresiva, la manera como todos los elementos mencionados (los cerdos que el despenador tiene que apartar, el fogón que llena de humo sofocante la escena) tienen una función en el relato consiguen la unidad de efecto de un relato extraordinariamente bien escrito y planteado. Su despenador es distinto tanto en el modo de actuar como en los rasgos descritos, y demuestran la gran originalidad de este escritor.

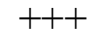

Jorge Moscol Urbina (1916-2002) se lanzó muy joven al terreno de la literatura y desarrollo una copiosa aunque desigual producción. Escribió cuentos magistrales y otros muchos relatos y novelas no tan rescatables, además de ensayos históricos algo insufribles, en donde, al decir de José Estrada Morales, "expresa bellamente y con propiedad el sentimiento piurano" (1966: 2), no solamente del campo de Sechura, donde se ubican sus cuentos más famosos: "Impuesto al piajeno", "El cholo capitulero", "La respetación" (precedente de "Etoy ronca" de Gálvez Ronceros). También en los barrios de una capital provincial vinculada todavía a formas tradicionales de subsistencia en torno a las haciendas y a trabajos manuales, pero que en los años 60 empieza a transformarse con la aparición de las universidades y se remece luego con la esperanza y el cataclismo de la Reforma Agraria y el colapso de las mal administradas cooperativas agrarias, lo que se refleja en sus relatos de Sombra de algarrobo (1977).

Era el tercero de cuatro hermanos. Fue profesor durante 38 años en el San Miguel, junto a Néstor Martos y Robles Rázuri, y recibió las Palmas Magisteriales en 1984, un año después de su retiro. Inicia también su carrera de periodista en 1936 con colaboraciones en "Ecos y Noticias", luego en "La Industria". Luego escribe una columna (firma siempre con sus iniciales JEMU) en "El Tiempo", donde permanece durante once años de intensas y agudas colaboraciones periodísticas. También escribirá relatos para la revista Piuranidad y artículos más extensos en Época. De 1945 es su novela Redención en el páramo. Tiene también relatos de viajes, como Crónica de un viaje a Iquitos (1958).

Cabe destacar los relatos breves de Moscol Urbina, alguno de los cuales han dado lugar a desarrollos posteriores de otros escritores. Confesión de una Madre Soltera (1945), es el relato breve de una joven que revela cómo quedó embarazada de un muchacho contrariando los consejos de la familia. Ella está a punto de desfallecer por una enfermedad mortal, ha dado a luz en su habitación en una ciudad extraña, pero quiere asegurarse de que sus padres reciban a la niñita que acaba de nacer. En el mismo volumen Moscol incluyó los cuentos: "Un milagro del señor de los milagros", "Las campanitas de San Sebastián", "Mis juguetes de Navidad", "El niño jugador", "Matrimonio por Poder". 
Cuentos sechuras (1967), con un prólogo de Luis Ginnochio Feijoo, reúne algunos de los cuentos más conocidos de Moscol. En ellos se muestra una gran madurez narrativa y una mayor finura en el humorismo de las escenas, la gracia de los diálogos y en el hábil manejo de la acción. Se ambientan todos en la singular comunidad de Sechura: "El engaño", "El cholo capitulero", "El hijo del cura", "El pedimento", "El día de las elecciones", "La respetación", "Impuesto al piajeno", "El padrino de uñas", "El licenciado", "Un sechura en París", "El maestro don Simón Garabatillo", y tres anécdotas recogidas por el autor en "La clásica chispa y lisura del poblador sechura".

Mangachería rabiosa (1986) se divide en realidad en dos partes con dos títulos independientes que hacen referencia al barrio norte de la ciudad de Piura, conocido como la Mangachería por haberse poblado mayoritariamente de los descendientes de negros esclavos traídos para trabajar en las haciendas desde la lejana Madagascar y que, desde mediados del siglo XIX, se ocupaban como zapateros, sastres o albañiles en la ciudad. En el primero, que sería propiamente el volumen con ese título, incluye "La lechucita mangache", "Los malgaches", "La coleta del torero", "Baibitas, baibón", "Ño Carnavalitos, Carnavalón", "El Ñato Monigote", "Ña Manonga Gatos" y "La Martinita como juguete". En la segunda parte, titulada Las travesuras de Simon Mon, se incluyen ocho cuentos más vinculados con el ambiente del barrio: "Cuando los mangaches rescataron a un prefecto", "El doctor Jojolí", "La guerra de los cascarones", "Los cuentos de Atavaliba", "Borrogoy el de los pavos", "San Chepito, el milagroso", "Pen, pen, por el río" y "El rapto de la Martinita". Con sus 212 páginas fue el libro de relatos más voluminoso que publicó Moscol.

En 1976 gana el primer premio de los Juegos Florales organizados por la Universidad de Piura. Al año siguiente publica Sombra del algarrobo (1977), que contiene una novela corta ("La chompa roja") y cuatro cuentos, de problemática urbana. Cuando Petroperú organiza en 1980 un concurso de cuento corto, su relato Romance en el coloche recibe el tercer premio (se publicó en 1982 y luego en 1991, junto con otros cuentos seleccionados por el autor de entre los "cuentos sechuras"). Trata el encuentro amoroso de campesinos indígenas o "amor indio", en las zonas rurales del bajo Piura.

Publicó también importantes obras históricas en que estudia especialmente el comercio y los transportes de la región en las obras: El comercio en Piura (1986), Cien años cultivando la amistad (del Club Centro Piurano), De los vicús al siglo XX. Cien años conquistando el desierto (1991). En 1995 publicó: Carlota, la piurana del siglo XX, biografia de la primera mujer diputada por Piura, con una presentación de Luis Chaparro que lo nombra "amauta del periodismo piurano". Jorge Moscol fue en verdad presidente de la Asociación de Periodistas de Piura. Formó parte también de la Junta de Obras Públicas en la que promovió la construcción de una carretera a Huancabamba, la pavimentación de calles especialmente en Talara y la construcción del teatro Manuel Vegas Castillo.

La despenadora (1944) es uno de los primeros libros publicados por Moscol, que incluye un relato bastante extenso, el que da título al libro, y otro más breve: "Las supersticiones de la Mechita". Como relatos tempranos, muestran muchas imperfecciones, se vuelven lentos en ocasiones y repetitivos, con exclamaciones gratuitas y alusiones innecesarias. Están ambientados en un ámbito rural no definido, en un lenguaje que luego se vertería con más nitidez en sus cuentos sobre mangaches y sechuras. La figura y el procedimiento del despenador son muy distintos: se muestra siniestro pero menos misterioso y más cotidiano: tiene nombre y domicilio conocidos; en lugar de greñas lleva la cabeza afeitada al rape y viste como los otros cholos, aunque se distinguía por llevar un pañuelo de vivos colores al cuello: "El rojo, decían las gentes, era la sangre de sus víctimas" (2008:131). 
El narrador se muestra más razonable, tratando de explicar la naturaleza del despeñamiento según el antiguo sistema (real o inventado) de creencias locales. El procedimiento finalmente no es nada tenebroso y sí muy expeditivo: propinaba un golpe seco con la nicula, garrote o vara de algarrobo, o ahogaba a los moribundos con su pañuelo. A continuación comía hasta hartarse y bebía interminablemente hasta el amanecer al lado de la tarima del que había despenado.

El relato en sí es un complicado enredo de acontecimientos en torno al matrimonio de Eustaquio y Patricia en el que la despenadora ayudará a darle una solución feliz. La madre de la muchacha, Eulalia Chumacero, emplaza a José Meche para que lo llame al orden al otro porque ha tumbado a la china, "barrigona está ya la lambida". Sorpresa, porque lo había visto al Eustaquio tan trabajador "lampeando de sol a sol" para juntar "unos pesitos para el casorio" (2008: 127), que le costaba creerlo, pero fue la vez del pedimiento, "se aprovechó de la borrachera". Reclamos, lloros y nada, que había que adelantar la boda para el día de la patroncita Rosa. Pero el Eustaquio es el más confundido de todos porque él no recordaba haber recibido "la prueba", aunque estuvo tan borracho que duda. José Meche está contento porque el cholo tiene espaldas anchas y manos calludas y como hombre sabrá responder.

Llegó la fiesta de Santa Rosa y entre los invitados llega ña Jacinta, que no le ha traído nada a la Patricia cuando todos traen zapallos, carneros, chanchitos, huevos, mantas, pabilo, de todo. Todas critican y no toman del mismo poto porque tenía fama de despenadora: "No vivía del oficio pero lo ejercía cuando lo estimaba conveniente" (2008: 131). Y era que al agonizar su hermana, hacía ya mucho tiempo, se había hecho despenadora: "El cura le había puesto los santos óleos, por lo que la María, en la buena fe de estas gentes, no podía seguir viviendo" (2008: 131) En su creencia, estaba lista para ir al cielo y de pisar la tierra cometería un sacrilegio y entonces moriría penada. Tendría que regresar a la tierra a "recoger sus pasos".

El Crisanto era el despenador de la región y efectivamente vivía muy lejos. Él había buscado ese aislamiento por cuanto todos huían de su presencia. Los chiquillos le arrojaban piedras cuando lo veían; los cholos lo insultaban y le decían "diablo en vida", y las chinas se persignaban y se escondían. (2008: 131).

Jacinta sabía echar las cartas y el rey de bastos "señaló a su hermana muerta y a ella la marcó como despenadora" (2008: 132). Bebió chicha con vichaya y entre las visiones recordó haber visto de niña al despenador por la rendija, cuando fue a despenar a su abuela y finalmente se acerca a su hermana: "Veyo la muerte en tus ojos, hermana", le dice y en ese momento que todo le parecía diabólico cubre el rostro de la agonizante con su manta hasta asfixiarla.

Luego volvió a hacerlo muchas veces y todas sin cobrar un centavo. Pero ahora había ido a participar de la boda y en la guitarra está Pacherres, el mejor cumananero de la región. Empezó a cantar bonito, porque luego de desertar del ejército había rondado a la Patricia. Y se cuenta el encuentro amoroso en el coloche y la promesa de hacerle un poncho. Pero la Jacinta había visto en las cartas que el Pacherres iba de mal en peor, lo habían detenido por unos chivitos y los padres arreglaron el pedimiento con Eustaquio. Pero la guitarra estaba lanzando un reto y el novio no podía "dejarse pisar el poncho". Pelea de cumananas hasta que el bandido canta desvergonzado la tercera para declarar que él "se había aprovechado de la novia un ratito", provocando la ira del novio y la huida de Pacherres. La novia se siente 
mal con "chucaque" y la Jacinta se encarga de todo: "Ya sabiya yo que tuesto iba a pasar puel facineroso del Parherres" (2008: 144).

En un rincón de la choza, al lado de un cántaro gordo de jora, echaba las cartas. Llegó el cura y se sentó a almorzar. Todo parecía perdido y hasta el cura se enferma del estómago. Pero la señora Jacinta lo cura y declara finalmente que ha despenado al cuatrero "por el callejón de la Chepa Santos" con un brebaje y ahogándolo con su manta "pa que no muriera penao y golviera ponde mi su espíritu malo" (2008: 149. La novia aborta y se descubre que Eustaquio era en realidad hijo de Jacinta, quien lo abandonó en la orilla del río con dos años de nacido: "no iba a tener felicidad conmigo porque era despenadora". El cura recibe su confesión y celebra el matrimonio finalmente como estaba previsto. Con cierto humor se escucha la voz de doña Eulalia, que se lamenta por la pérdida del nieto: "Puel Pacherres facineroso y desgraciao, que en paz descanse, me quedé sin nieto" (2008: 150). En verdad el relato es un desbarajuste de historias diversas sin un estilo definido: intriga, terror, amor y risa todo en un mismo lugar. El cuento tiene seis capítulos o episodios y un epílogo extrañamente amargo: una noche oscura la despenadora se ahorca en un faique.

Moscol procura hacer más creíble la figura de despenador y al mismo tiempo termina condenándola a su extinción. Hay inconsistencia entre la premura y la lejanía, y el argumento se torna enredado y antojadizo, pero ofrece una versión curiosa de despenadora en una mujer que se compadece, que se reconoce no integrada en la sociedad y que finalmente resuelve la situación por su propia iniciativa pese a que se presenta sin intención alguna de ejercer su oficio.

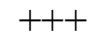

El escritor y diplomático piurano Francisco Vegas Seminario (1899-1988) es autor de una nueva versión de esta figura literaria. Había publicado varios cuentos de ambiente regional en Chicha, sol y sangre (1946), con un prólogo elogioso de Ventura García Calderón, compuesto por catorce relatos. En su segundo libro de relatos, titulado también con cierta nostalgia: Entre algarrobos (1955), vuelve a incluir el cuento "El despenador" (117-124). En ese mismo volumen se incluían los relatos: "Entre algarrobos", "Las orejas de Centurión", "La momia del cacique", "Absolución de plomo", "El primogénito de los Godos", "Taita Dios nos señala el camino". Salvo los dos primeros, todos formaron parte de su primer libro, publicado en París y apenas difundido en Perú. Publica también relatos en revistas, como Piuranidad, "La subconciencia manda" (1956) de modo que siguió vinculado a su Piura natal, especialmente luego de su retiro de la carrera diplomática

Vegas también publicó diez novelas, entre las que hay algunas de carácter histórico, aunque las mejores son las de tema telúrico: Montoneras (Premio Nacional de Novela en 1954) y sobre todo Taita Yoveraqué (1956). El mayor reparo que puede hacerse de la narrativa de Vegas Seminario es la lentitud y torpeza con que arma la acción, con algunas páginas confusas o pesadas, pero cabe rescatar la fuerza de los diálogos, la intensa personalidad de sus personajes y en general la simpatía con que presenta la problemática y el ambiente en que se mueven el conflicto, simpatía que se refleja con claridad en una innegable gracia en el empleo del lenguaje, aunque a veces el abuso de regionalismos conlleva también cierto cansancio. La simpatía de Vegas Seminario era parte notable de su personalidad y la advirtió perfectamente Vargas Llosa cuando lo entrevistó para el suplemento cultural del diario El Comercio de Lima (Rodríguez Rea, 1996: 61). Y la simpatía era también lo que destacaba con especial énfasis García Calderón en su prólogo: 
Costumbres, supersticiones, tipos genuinos de la provincia, simpatía irresistible que despiertan por su compleja psicología, en donde suavidad y dureza suelen juntarse, todo es específicamente nuestro. Y si veo con nitidez las fallas de mi gente peruana, me apresuro siempre a recubrir con un velo de simpatía las estridencias de aquella fauna non sancta, viviente y maleante. ¿Sabéis por qué? Porque de este libro surge con su perfume vivaz de chirimoya la imagen misma de la patria. Del Perú como fue ayer, como sigue siendo, con sus hombres finos, pendencieros, mujeriegos, revolucionarios, lunáticos, alguna vez "palanganas" como dice nuestro peruanismo insustituible, todo lo que Vegas Seminario vio en su juventud y yo en la mía". (1946: 11)

Vegas Seminario, perteneciente a una rama de lo que fue la más importante familia de hacendados norteños, estudio en el colegio San Miguel y luego, en Lima, en la Universidad de San Marcos. Cuando regresa a Piura, se inicia en el periodismo, pero en 1932, asume el gobierno de la nación el general piurano Luis Miguel Sánchez Cerro. Varios piuranos serán ministros o consejeros del nuevo presidente. Vegas Seminario ingresa entonces al servicio diplomático, ejerciendo diversas responsabilidades en Marsella, Polonia, Checoslovaquia, Brasil, Italia, Venezuela, Chile y Costa Rica. Se retira del ejercicio en 1968 para residir sus últimos años en Lima, ciudad donde murió el 14 de enero de 1988.

Vegas es un típico representante de la literatura telúrica y de la narrativa basada en motivos populares, regionales o folclóricos, con cierto desaliño en el estilo y un manejo muy tradicional de la técnica narrativa (González Vigil, 1991: 225-226). Muy apreciado en su tierra natal, se le ha valorado especialmente por ser "casi un espejo de la auténtica realidad", por lo que su obra posee "emotiva y sustancial resonancia" (Estrada Morales, s.f.: 8).

A Vegas Seminario en verdad no le preocupaban las técnicas literarias y cree que lo fundamental es imaginar un motivo: "El tema es lo único que importa -le decía a Vargas Llosa - imaginado éste, lo demás sale solo" (Rodríguez Rea, 1996: 61). Entre los escritores americanos que más le han influenciado están Rómulo Gallegos y José Eustaquio Rivera. Admira a Valle-Inclán y a Pérez Galdós, y entre los extranjeros declara haber sido cautivado por La montaña mágica de Thomas Mann y La noche quedó atrás de Jan Valtin. En el momento en que el joven Vargas Llosa le entrevista (setiembre de 1955), Vegas gozaba de cierta popularidad y disfrutaba de la amistad de los círculos literarios que apreciaban su modestia y su desbordante simpatía natural (Rodríguez Rea, 1996, 61).

La trama del relato "El despenador" es compleja y se divide en dos partes. Encontramos personajes buenos y malvados en un mundo de pequeños ranchos alejados entre los campos de algodón. Los diálogos se suceden con rapidez y llegan a ser corales, con algunos leit motiv "una semana más", "su agonía dura, dura". Remedan imperfectamente las técnicas cinematográficas pero consiguen crear una atmósfera verosímil. A veces representan voces anónimas que reflejan el sentir popular. "Se lo llevan los espíritus que tiene en el cuerpo" (1994: 129). Estrada Morales destacaba en el cuento "sabor a tierra, supersticiones rediviva", señalando la pervivencia del viejo y fantasmagórico despenador "todavía se les ve por los campos acotando la vida de los moribundos" (s.f. 23).

José de la Luz Ancajima siente un fuerte malestar y sospecha que los cocimientos o brebajes que le prepara su esposa no le hacen bien, antes al contrario. Pero se los toma por no contrariar a la mujer. El vecino, "un cholo de ojos mongólicos y maliciosos" (1994: 123), se hace cargo de los quehaceres en la chacra pero pronto advertimos que tiene no solo "tiene voluntad" (1994: 125), como dice la Natividad, sino que también tiene ya una relación 
amorosa con ella y todo eso lo sospecha el curandero hasta de que están envenenándolo por ese motivo. Tratarán de acallarlo con el regalo de un pollino. Y finalmente llaman al despenador. El escritor se siente obligado a poner una nota explicativa:

Despenadores existieron en ciertas regiones del Perú, pobladas por indios, hasta mediados del siglo pasado (Vegas, 1994: 125).

Con su sola mención un "fuerte estremecimiento sacudió al enfermo" (1994: 125). José de la Luz reclama pero obedece. El despenador es descrito en términos despectivos: es una "parca sin guadaña" o una "parca cobriza", y se asemeja a una sombra de la muerte de cine de terror:

Indio mitad hechicero mitad bandido, el despenador, cuyo nombre nadie conocía en la región, podría tener cincuenta, setenta o cien años. Pero para aquellas gentes pasaba por inmortal, tres generaciones lo habían visto con el mismo aspecto de ave agorera, descendiendo al llano cada vez que alguien se hallaba en trance de muerte. Guiado por misterioso instinto, caminaba siempre entre tinieblas, y tan pronto penetraba en el rancho del enfermo, corría a esconderse bajo su lecho, en donde esperaba el momento propicio para saltar sobre el desdichado, clavarle la rodilla en el vientre y apretarle el cuello. (1994: 129-130).

El procedimiento seguido en el despenamiento aparece como un arrebato de salvajismo para "acortar la agonía de los moribundos, despenarlos, como decían las supersticiosas gentes del lugar" (1994: 132). A lo largo del relato se deslizan esas notas reiterativas amenazantes: "un vago rumor" (128), "ese penoso sopor que le envolvía la mente" (128), "rumor de estertores (132), y especialmente las alusiones a la oscuridad: "sus tinieblas interiores" (128) "la estancia ensombrecida" (1994: 130). El despenador se asocia a las lechuzas, cuyo canto indica la proximidad de la muerte. En la creencia local es el "cau", el ave de mal agüero (Palacios, 1995: 47), que para otros es un animal de aspecto feo y horrible (Puig, 1995: 55). ${ }^{3}$ En el relato se alude a que viene de la sierra y vive en una cueva. Hay que ir a llamarlo pero de igual modo llega:

El huele donde hay moribundos, entonces deja su cueva y baja corriendo. Las lechuzas le cuentan también todo pero él espera la medianoche para entrar. (1994: 131)

En verdad sus relatos son un "mosaico de personajes y aventuras", como señalara Estrada Morales, "un pequeño mural piuranísimo" en el que el escritor vuelca su añoranza por su tierra. Y así está muy presente la memoria de las vivencias familiares: José de la Luz "recordaba haber visto en su niñez al temido y repugnante personaje cuando su madre se hallaba en agonía" (1994: 131), y haberlo visto entrar "desgarbado, esquelético, con el sombrero alón aplastándole una maraña de greñas hirsutas; lo veía luego escurriéndose bajo el lecho y saltando más tarde sobre la afligida mujer" (1994: 132). Todos los adjetivos están asociados a falta de vitalidad: delgadez, flacidez, y lo que destacan más bien son sus manos que luego se mencionan como "las garras de aquel espectro", "los tentáculos horribles de sus manos" (1994: 132).

\footnotetext{
${ }^{3}$ La sombra tiene una importante presencia también en las supersticiones piuranas. En el sistema de creencias locales, evoca al espíritu, no el alma del paciente. "La enfermedad quita la sombra ya sea por susto o por viaje en el que el maestro o curandero va con la sombra por llamada de los maleros." (Puig, 1995: 135)
} 
En la escena final que ladran los perros ante la llegada del despenador José de la Luz adquiere una inusitada vitalidad para arrastrarse, tomar una fuerte vara de algarrobo y golpear con ella al malicioso pretendiente para luego recostarlo en la barbacoa para que el despenador lo ultimase a su manera. Por fin aparece este como "un indio magro y haraposo", con un poncho de "indefinible color", un pantalón desgarrado que dejaba ver "piernas largas y flacas" y las usutas "pies negruzcos y retorcidos" (1994: 133). ${ }^{4} \mathrm{Al}$ final "se fue como un fantasma" (1994: 134). Igual muere el enfermo, pero antes tiene tiempo de disfrutar de la escena y de condensar su último aliento en una pregunta: “¿Estás ahora satisfecha, Natividad?" (1994: 134).

El tema del cuento, evidentemente, es "el placer de la venganza, sentimiento que solo los indios saben apreciar en toda su extraordinaria exquisitez" (1994: 134), que evidentemente debe mucho a los cuentos de García Calderón. Pero en el relato también aparecen otros motivos que se repiten en Moscol Urbina y otros autores de la literatura regional, como el encuentro amoroso en el "coloche" (terraplén que encauza el río) o el engaño promovido por mujeres.

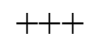

Luego el escritor paiteño Teodoro Garcés Negrón (1897-1981) escribe un conocido relato de despenadores. Fue un asiduo colaborador de La Industria y de otros periódicos de Piura con sus "Crónicas piuranas", y autor de un Romancero piurano (1965). Caracterizado por un lenguaje festivo e ingenioso a la vez que por la fina sensibilidad con la que describe lugares y personajes de la región. En sus relatos trata también de reflejar incluso de forma más exacerbada los modos de la pronunciación local y así se dificulta grandemente su lectura, que de todos modos encuentra caminos para trasmitir una peripecia de singular interés. Sus relatos eran poco conocidos, pero póstumamente se publicaron sus cuentos en la colección Perulibros promovida por Juan Mejía Baja con el apoyo de la Biblioteca Nacional del Perú, que es hoy fácilmente accesible a través de los portales de internet de la misma Biblioteca o de la Comunidad Andina de Naciones. También se publicaron en la colección "Cuentos Piuranos" del Centro de Investigación y Promoción del Campesinado en 1991.

Garcés Negrón fue un contador público y periodista piurano, compañero de Vegas Seminario en el semanario La Prensa, en 1921, muy cerca del escritor Enrique López Albújar, quien le impuso el mote de "el Cura". Junto a ellos el profesor Francisco Sandoval, amigo y compañero de estudios de César Vallejo. Todos profesores del Colegio Nacional San Miguel. Con los años serán remplazados por Jorge Moscol Urbina, Néstor Martos y José Hipólito Estrada Morales, cuando Sandoval se muda a Trujillo, en 1949 y López Albújar y Garcés Negrón pasan poco después a radicar a la capital. Garcés Negrón se formó como toda esta promoción norteña en las aulas llenas de vitalidad y de ideas nuevas de la Universidad de Trujillo, con profesores estimulantes como José Eulogio Garrido, Antenor Orrego y Francisco Izquierdo Ríos. Como ellos, tuvo una activa participación política, pues formaría parte del grupo fundador del Partido Aprista en Piura, pasando a la clandestinidad en varios momentos. Fue en algunos periodos regidor de la ciudad y también propietario de una librería ubicada en la céntrica calle Tacna, muy cerca del domicilio donde vivió Vargas Llosa en 1952.

\footnotetext{
${ }^{4}$ El color del poncho está asociado generalmente a comunidades campesinas concretas, con lo que así se refuerza la idea de un origen misterioso.
} 
Garcés Negrón pone siempre una nota de humor en las situaciones más desesperadas y es algo ambiguo porque nos lo muestra desde los ojos de un testigo como "mi amigo el despenador". Trata de justificar su terrible actuación porque con los lamentos "no pueden descansar los mayores ni dormir los churres" (81). No podrán atender al cuidado del enfermo cuando llegue la paña, la cosecha del algodón. En realidad son dos relatos diferentes con un mismo protagonista, don Ciriaco, en una mezcla de relato de terror, realismo mágico, estampa costumbrista y comentario político y social.

El despenador cumple su labor por duplicado: por un lado ultima a un tal Yovera, castigado por ocioso, y luego mata a un serrano con el detalle humorístico de que le reclama una plata al despenador que lo silencia. Garcés consigue momentos de gran fuerza narrativa, detallando con cruda agilidad la manera con que el despenador imponía las rodillas en el pecho de los ancianos y los ahogaba con sus fuertes manos. El modus operandi difiere de otras prácticas descritas, pero también en el relato mismo hay divergencias: primero el despenador llega sin ser llamado y aparece y desaparece sin que casi nadie pueda verlo, casi como un fantasma, a altas horas de la madrugada. En el segundo caso, en cambio, es un vecino que acepta el encargo en pleno día y al final recibe su paga: siete pesos y dos sortijas de oro.

El tópico indigenista aparece como justificante absoluto: don Cipriano es "heredero de la ética de los antiguos tallanes", y su superioridad moral se basa en una burda presunción de inocencia: "Los antiguos sabían más que los blancos que sólo quieren oro", aunque este Cipriano se llevará al final, por supuesto, las sortijas, además de la herida que le dejó el agonizante, al tratar de defenderse mordiéndole el brazo. A Cipriano "nadie le perdía el respeto, y como decían que había matado a varios bandidos en sus años mozos, lo miraban con cariño" (83). Y de todos modos, seguía una tradición antigua: "Los viejos guardamos muchos secretos y cumplimos sus costumbres". Otra justificación gratuita.

Me parece interesante que en el relato hay elementos mágicos que de alguna manera expresan la inmoralidad del acto, que son la amarra colorada que distingue al oscuro oficiante y la mordedura de muerto que "no se cura". El despenador, pues, está señalado o marcado con el color de la sangre y la herida que sufren por ejercer ese oficio eugenésico no tiene remedio en este mundo: no puede subsanarse con nada.

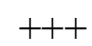

Herbert Morote es un escritor tardío con una trayectoria fuera de lo común. Siempre tuvo una fuerte vocación literaria pero despuntó en una talentosa carrera empresarial asumiendo diferentes cargos de dirección y gerencia de empresas vinculadas con el ámbito farmacéutico en Perú, donde fue también profesor fundador de la Universidad de Lima, y director del Instituto Peruano de Administración de Empresas (IPAE). En 1970, tras el golpe de estado del general Velasco y el comienzo de su dictadura militar se establece en México y luego en Estados Unidos, igualmente vinculado a la dirección de empresas, hasta que en 1990 abandonó los negocios y comenzó una nueva vida de escritor en Madrid con la novela Suerte para todos (1995), y varias obras de teatro, como Los ayacuchos (1991) y Olivia y Eugenio (1993). Es autor de diversos ensayos que han generado varias polémicas, como los dedicados a Simón Bolívar y a Mario Vargas Llosa, con quien fue compañero de estudios en La Salle y en el Leoncio Prado. 
Tuvo cierta presencia mediática cuando acusó a Alfredo Bryece Echenique de haberle copiado un capítulo entero de uno de sus ensayos. Bryce reconoció solamente que para escribir ese artículo le había sido muy útil el ensayo de Morote. Julio Ortega y otros críticos apoyaron a Bryce aunque ahora muchos reconocen que el escritor cometió plagio en este y algunos otros casos.

Morote es autor de una novela: Suerte para todos, que se ha publicado en España (Barcelona, Seix Barral, 1994), México (Seix Barral, 1995) y en Perú (Lima, Yachay, 2000), un relato detectivesco en torno a un ejecutivo asesinado, que se sitúa entre Acapulco y la costa central de California. Además publicó tres relatos mucho más breves, en su propia página web de internet. Entre ellos un cuento de cierta extensión fechado en 1998: "El último despenador".

Con un tono desenfadado y actual, y ningún interés por el folclore o las creencias populares, Morote construye un relato en el que el despenador sirve para aumentar el dramatismo de dos escenas. En primer lugar dos hermanos lo llaman para terminar con la agonía de su anciano padre en un pequeño poblado de los Andes. Pero hay rencillas entre ellos y Sinencio odia a su hermano Juanacho porque se fue a estudiar a Santiago de Chuco y nunca más volvió a Quispac. Además, el anciano padre quiere que Juanacho herede unas tierras en el páramo donde presume hay buenos prospectos de plata y zinc: podrían valer una fortuna. Sinencio no se contenta con su parte de herencia y envenena a su hermano, quien sin embargo logra reunir fuerzas para empuñar una pistola y obligar al despenador a que sea él quien mate violentamente a Sinencio, para después matar también al último despenador.

En el cuento resultan un poco chocantes los diálogos no tanto por asumir lenguaje muy moderno, y emplear groserías, sino porque en muchos casos se trata de jergas urbanas: “¿Estás muñequeado, hermano? ¿Estás pensando que es veneno, rosquete?” La falsedad y la criollada de Sinencio se revelan de este modo con un lenguaje duro y directo: "Puta madre, que ladrón eres. Pero todo sea por mi pobre hermanito, está sufriendo. Que sean los trescientos, pues."

El relato posee gran eficacia narrativa. El despenador apenas se describe con tres adjetivos: "era un viejo horrible, huesudo y desencajado", y dos notas alusivas a sus garras: "Juanacho aguzó la vista al máximo y pudo ver la mano huesuda del Despenador, con sus uñas largas y negras, contando el molido". Su llegada es tenebrosa: "todo oscureció y una sombra entró en la habitación". No hace falta que nadie lo llame porque él sabe dónde hay un agonizante. Pero al mismo tiempo tiene sus tarifas diferentes para cada tipo de trabajo. El procedimiento que emplea no se explicita en ningún caso. Lo único que trasciende es el discurso del despenador: “¿Me oyes, hijo?, vengo a quitarte las penas. Te aseguro que hoy día mismo estarás en el reino de los cielos." Es bastante evidente la distancia desmitificadora que impone Morote al tópico, resolviendo todo con un disparo final y empleando una frase evangélica en un contexto terrorífico, al más puro estilo de las películas.

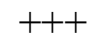

En la última novela de Mario Vargas Llosa, "El héroe discreto", el protagonista conversa en varias ocasiones con la señora Adelaida, que le aconseja porque posee un don para adivinar y siempre le vienen de repente inspiraciones de si algo saldrá bien o mal. Y entonces el narrador empieza a añadir detalles folclóricos: 
Felícito se sorprendió al oír contar a Adelaida que en el pasado reciente había incluso en Piura unas mujeres tenebrosas, las despenadoras, a las que ciertas familias llamaban a las casas para que ayudaran a morir a agonizantes, algo que ellas hacían entre rezos, cortándoles la yugular con una larguísima uña que se dejaban crecer en el dedo índice con ese propósito" (2013: $363)$.

Dos décadas antes los había mencionado apenas en Lituma en los Andes, donde al menos la temática folclórica resulta más justificada. En efecto, el sargento piurano reflexiona sobre las creencias andinas:

Yo, al menos, no he sabido que haya pishtacos en Piura. Despenadores, sí, conocí uno, en Catacaos. Lo llamaban de las casas donde penaban las ánimas para que las apalabrara y se fueran. $(1993: 65)^{5}$

Sorprendentemente aquí se trata de otra cosa: Vargas Llosa confunde los despenadores con desencantadores o cazadores de fantasmas. Y cuando habla de la despenadora en su última novela no alude realmente a costumbres o tradiciones reales o supuestas de Piura o el desierto norteño, sino que el modo como registra la figura del "despenador" es nuevamente la viva imagen que había dibujado Ricardo Palma en 1878.

En el noroeste de Argentina, hallamos una mención breve al despenamiento en una novela de Cristina Bajo (1937) también maestra y periodista reconocida tanto en su Córdoba natal como en toda la nación por sus novelas de corte sentimental. Obtuvo el premio de la Academia Argentina de Letras en 2004. Pues bien, aparece una despenadora en uno de los relatos de la Saga de los Osorio, concretamente En tiempos de Laura Osorio (2011):

Don Goyo venía herido y dicen que le agarró la gangrena y olía como mula muerta. Ya se veía que el hombre no iba para sanar, pero no terminaba de estirar la pata. Así que él mismo hizo llamar a la Cora y le pidió que lo despenara; hasta le ofreció oro. Pero ella le dijo que lo iba a hacer de voluntá, no más. (2008: 46).

El procedimiento que sigue no es el degollamiento, como cabe suponer, porque "ella no derrama sangre", pero Cora "dulce y callada, con esos ojos que parecían mirar a través de las cosas", sabía cultivar "yuyos para curar y yuyos para matar". Y en esta ocasión fue con una canción que duró toda la noche hasta que se acalló el último latido del enfermo. Se trata por supuesto de una invención tranquilizador. Se han señalado varios casos de eutanasia criolla en las regiones andinas de Argentina. Particularmente Rafael Cano (1930) declaraba haber conocido a un nonagenario hacia 1880 que supo ganarse la vida despenando, y había aprendido el oficio de un viejo al que asistió como criado. Ponía la rodilla en la espalda del desahuciado y palando violentamente los brazos para atrás partía la columna del enfermo. $\mathrm{O}$ bien oprimía con los dedos pulgares las cervicales. También menciona una mujer despenadora llamada ña Micaila que ponía la rodilla sobre el esternón.

\footnotetext{
${ }^{5}$ También más adelante menciona el oficio en una enumeración de abusiones: "Que tenía mujeres e hijos por todas partes, que había muerto y resucitado, que era pishtaco, muki, despenador, brujo, estrellero, rabdomante. No había misterio o barbaridad que no se le achacara." (1993: 243).
} 
Es muy probable que en Argentina y Bolivia existan relatos regionales que tengan como protagonista al despenador pero no hemos podido hallar ninguno.

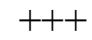

En la Isla de Ustupu, una de las más interesantes del archipiélago de San Blas o de las Mulatas, en Panamá, los indios cunas usan el extracto del ina nusu para curar las lombrices de los niños como infusión, pero concentrada por ebullición la hierba produce una substancia mortal, un alcaloide parecido a la nicotina. Bastan cuatro o cinco gotas bajo la lengua para acabar con la vida de cualquier ser humano, cosa que hacen cuando quieren "despenar" a alguien que padece una enfermedad incurable o bien es demasiado viejo para poder valerse por sí mismo.

Los chamanes tardaron siete años en darle a conocer el secreto al doctor Reverte, señal de la vergüenza y el respeto que otorgaban al peligroso veneno. El mundo moderno trata de controlarlo todo y en ello también se incluye un protocolo para la muerte. El debate reaparece con cada nuevo caso (el de José Luis Sampedro generó luego la película Mar abierto), y a menudo tratan de justificarse en la presunta "naturalidad" de las culturas ancestrales, pero estas sienten igualmente el temor y la vergüenza, el dolor por el mal que está inscrito en el corazón de todos los seres humanos. Claro que siempre pueden darse razones para justificar lo irreparable, aunque la huella que deja la mordedura, el daño moral que afecta al despenador y a su comunidad por permitir y justificar la muerte violenta de un enfermo inocente no pueda borrarse nunca con nada.

\section{REFERENCIAS BIBLIOGRÁFICAS}

ABAD DE SANTILLLÁN, Diego (1976): Diccionario de argentinismos de ayer y de hoy. Buenos Aires, Tipográfica Editora Argentina.

ALCALÁ VENCESLADA, A (1998): Vocabulario andaluz. Edición de I. Ahumada. Jaén, Universidad de Jaén / Cajasur.

ARÁMBULO PALACIOS, Edmundo, Diccionario de piuranismos. Piura: Municipalidad Provincial de Piura, 1995.

BAJO, Cristina (2008): En los tiempos de Laura Osorio. Buenos Aires, Sudamericana.

CANO, Rafael (1930): Del tiempo de ñaupa; folclore norteño. Buenos Aires, Talleres Gráficos Argentinos de 1. J. Rosso.

CORNEJO POLAR, Antonio (1989): La formación de la tradición literaria en el Perú. Lima, Centro de Estudios y Publicaciones.

COVARRUBIAS, Sebastián de (2006): Tesoro de la lengua castellana o española. Edición de I. Arellano y R. Zafra. Pamplona / Madrid, Universidad de Navarra / Iberoamericana.

DÍAZ FALCONÍ, Julio (2005): Cronología de las Tradiciones. Lima, Universidad Ricardo Palma.

ESCAJADILLO, Tomás (1986): Narradores peruanos del siglo XX. La Habana, Casa de las Américas.

ESCOBAR, Alberto (1960): La narración en el Perú. Estudio preliminar, antología y notas. Lima, Juan Mejía Baca.

ESTRADA MORALES, José H. (1966): "Introducción” a Cuentos piuranos. Piura, Gran Unidad Escolar San Miguel, 1966, p. 2. 
_ Francisco Vegas Seminario. Acercamiento a las orillas de su fuente. Piura, Cuadernos de Piuranidad, s.f.

FLORES, Ángel (1959): Historia y antología del cuento y la novela hispanoamericana. New York, Las Americas,.

GARCÉS NEGRÓN, Teodoro (1988): "Mi amigo el despenador", en La embestida del carnero y otros cuentos. Lima, Biblioteca Nacional del Perú, 1988, pp. 81-86.

GARCÍA CALDERÓN, Ventura (1924): "El despenador", en La venganza del cóndor. Madrid, Mundo Latino, 1924, pp. 161-172.

(1989): Obra literaria selecta. Edición y prólogo de Luis Alberto Sánchez. Caracas, Biblioteca Ayacucho, 1989, pp. 191-192.

GONZÁLEZ VIGIL, Ricardo (1991): El cuento peruano, 1942-1974. Selección, prólogo y notas. Lima, Ediciones Copé.

KRISTAL, Efraín (1988): "Del indigenismo a la narrativa urbana del Perú. Revista de Crítica Literaria Latinoamericana. 14 (27).

LARCO, Laura, Más allá de los encantos. Documentos históricos y etnografía contemporánea sobre extirpación de idolatrías en Trujillo, siglos XVIII-XIX. Lima, Universidad Nacional Mayor de San Marcos / Instituto Francés de Estudios Andinos, 2008.

MARROQUÍN, José (1940): "La medicina indígena puneña", en Anales de la Sociedad Peruana de Historia de la Medicina, 2, 1940, pp. 42-57.

MORINIGO, Marcos A. (1998): Nuevo Diccionario de Americanismos e Indigenismos. Buenos Aires, Claridad.

MOROTE, Herbert, "El último despenador", disponible en la página web del autor: http://www.herbertmorote.com/despenador.asp

MOSCOL Urbina, Jorge E. (1945): Confesión de una Madre Soltera (y otros cuentos). Prólogo de Néstor Martos. Piura, Agencia Moderna(?).

- (1977): Sombra de algarrobo. Cuentos Piuranos. Volumen I. Piura, Impresos San Antonio.

(1986): Mangachería rabiosa. Lima, Editorial Piuranidad.

(1991): Romance en el coloche. Piura, Centro de Interpretación y Promoción del Campesinado.

NÁJAR, Jorge (2014): La compañía del Alto Putumayo. Lima, Summa.

OVIEDO, José Miguel, y otros (1969): Primer encuentro de escritores peruanos. Lima, Latinoamericana.

PALMA, Ricardo (1893): “Juan Sin-miedo", en Tradiciones peruanas. Quinta serie. Barcelona, Montaner y Simón, 1893, tomo III, pp. 34-37.

PUIG TARRATS, Esteban (1995): Breve diccionario folclórico piurano, Piura, Universidad de Piura, $2^{\text {a }}$ edición.

REVERTE COMA, José Manuel (1983): Las fronteras de la medicina: límites éticos, científicos y jurídicos. Madrid. Editorial Díaz de Santos.

RODRÍGUEZ REA, Miguel Ángel (1983): “El cuento peruano contemporáneo. Índice bibliográfico I. 1900-1930", en Lexis, 7, 1983, pp. 287-309.

(1996): Tras las huellas de un crítico: Mario Vargas Llosa. Lima, Pontificia Universidad Católica del Perú,.

VARGAS LLOSA, Mario (1993): Lituma en los Andes. Barcelona, Planeta.

- (2013): El héroe discreto. Barcelona, Alfaguara.

VEGAS SEMINARIO, Francisco (1946): Chicha, sol y sangre. París, Desclée de Brower. 
- (1956): "La subconsciencia manda", Piuranidad. Arte, Ciencia, Letras. N. 2, Diciembre de 1956, p. 47.

(1955): Entre algarrobos. Lima, Círculo de Novelistas Peruanos,.

(1994): "El despenador", en Chicha, sol y sangre. Piura, Instituto Cambio y Desarrollo / Concejo Provincial de Piura, 1994, pp. 121-134.

VIVANTE, Armando (1953): Muerte magia y religión en el folklore. Buenos Aires, Lajouane.

(1956): "El despeñamiento en el folklore y la etnología", en RUNA. Revista de la Facultad de Filosofía y Letras de la Universidad de Buenos Aires, 7, 1956, pp. 209233.

(C) Carlos Arrizabalaga

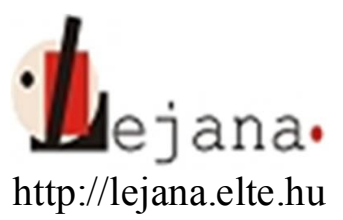

Universidad Eötvös Loránd, Departamento de Español, 1088 Budapest, Múzeum krt. 4/C

Recibido: 28 de septiembre de 2015

Aceptado: 10 de octubre de 2015 